\title{
The research on Chinese college curriculum reform based on post-modern curriculum theories
}

\author{
LV taifu ${ }^{1, a}$ \\ ${ }^{1}$ Linyi University, Linyi Shandong 276400,China \\ a51557997@qq.com
}

Keywords: post-modern; curriculum theory; university courses; reform

\begin{abstract}
With the development of economy and society, the Chinese university education becomes increasingly popular and also faces many difficulties in which the curriculum reform is the core for modern university reform. The post-modern curriculum theories by Dole affect the university curriculum reform greatly. In the point of view of post-modern curriculum theories, the curriculum objectives should not be pre-defined. The university curriculum contents are not absolutely objective and stable knowledge system in which the implementation of curriculum should not mainly base on instilling but the process with teachers and students.

The traditional college courses have a lot of flaws and defects and the coherence among educational disciplines is not high. However, the cultivation of scientific spirits and the fusion of scientific branches are ignored which cannot meet the requirements of post-modern society and development of human. The needs for curriculum reform are necessary. This paper is mainly about college curriculum reform with post-modern curriculum theories.
\end{abstract}

\section{The post-modern curriculum theories}

In the 1960s, post-modernist ideology began to affect people's learning and life and change people's views about value. The post-modernism is the latest development trend of Western philosophy, which emphasizes the reality and criticism, advocates irrationalism, opposes centrism, advocate to solve problems by multiple perspectives and diversified methods. The post-modernist has the typical features of diversity, creativity, openness, contradiction, arbitrariness and so on. The post-modern curriculum theories are based on after-modernism and post-modernism philosophy and culture. The post-modern curriculum theories think the university curriculum education cannot purely pursue stationary mode of education, but with the rebuild by combing the latest philosophy and psychology ideas. Slattery is a typical representative of the post-modernism curriculum theories who said that the curriculum study began to integrate the philosophy topics into curriculum and teaching since the reconstruction of curriculum research. The post-modern curriculum theories propose a new point of view of curriculum by critiquing the Western curriculum system controlled by tool theories. There are many features. The modern curriculum views emphasizes scientific, rational, and logical. They think the courses are pure scientific and advocate the courses should focus on scientific knowledge with the features of close, uniform and predictable, etc. The students cannot open their minds to think about the complicated modern society. The post-modern curriculum by Dole critiqued these in details. He think the modern curriculum theories are too close, simple and rigid while the post-modern curriculum theories emphasize openness, complexity and transformative. Dole believes the principles of modernism by Taylor closed the curriculum. In order to overcome the deficiencies of Taylor theories, Dole proposed the corresponding 4R curriculum standards, namely richness, relevance, recursive and rigor which emphasize the mutual integration of various disciplines. In the point of view of post-modernism, the goals of university curriculums are dynamic changing with the time and it's hard to be predicted. The course contents are not static which should be updating with the development of society. For the curriculum implementation, it is a generation process which is not simply indoctrination and explanation, but a dynamic process. 


\section{R curriculum standard analysis by Dole}

\section{(1) Richness}

The feature of richness in the 4R curriculum standard emphasizes the abnormalities, ambiguity, and imbalance in the courses, which are proposed aiming at the fixed and closed curriculum theories in the modernist course theories. However, it's difficult to stimulate the innovation without losing the forms which is hard to predict and needs the coordination among teachers, students and text books. The academic knowledge taught in university education has its own development characteristics and backgrounds. Each discipline has its own explanation characteristics. The richness in Dole's theories is beneficial for the cooperation and mutual penetration among disciplines.

(2) Recursive

The recursive curriculums in higher education don't have fixed start and end points. This recursive isn't unlike the repetitive close framework in the modernist curriculum theories. The modernist curriculum theories increase the students' grades through fixed programs which are by flexible and communication ways in Dole's post-modern curriculum theories. Dole thinks the recursive will become repetitive and lost freshness without communication and meaning of regression.

(3) Relevance

The relevance promotes the transformation of post-modern curriculum theories from educational and cultural aspects. From educational aspect, it mainly refer to all of the problems and their association in the firmware courses in university education, such as the relationship in course structures. From cultural aspect, it mainly emphasizes the association between culture and nature beyond the courses, namely it emphasizes the prerequisites for teaching activities. The communication can link various problems to provide a unique sense of culture which are helpful for students to learn and understand cultural knowledge.

(4) Rigorous analysis

Dole proposed the rigorous analysis in $4 \mathrm{R}$ curriculum standard which is a kind of redefinition of knowledge concepts. The rigorous analysis positively seek curriculum hypothesis by searching different options for effective communication and the purpose of learning. The rigorous analysis has characteristics which is an information integration process.

\section{The state of art of university curriculum reform}

With the deepening of China's university education development and reform, there are more and more problems affecting educational reform which is mainly about the gaps between the talents cultivation and social demands. The reasons for the gap are that the current high educational curriculums cannot satisfy the social demands. The traditional curriculum education pre-defines the curriculum objectives, the curriculum knowledge systems are quite fixed and the measures for implementation are very lag behind. All of the issues seriously restrict the further development of higher education reform. Now, there are lots of contradictions and difficulties, such as the contradictions between curriculum configuration and talents cultivation, between the course contents and professional positions, between actual abilities and social demands, between the current curriculums and infinite knowledge, and between stable curriculum systems and flexible personnel demands. The series of conflicts in the higher education curriculums cannot be solved by simple reform because the higher education is a continuous and dynamic process. The relevance feature in the post-modern curriculum reform can help solve the contradictions in the higher education curriculums. 


\section{The effective measures for Chinese university curriculum reform with post-modern curriculum theories}

The post-modern curriculum theories are proposed aiming at the modern curriculum theories, which is not only the introducing of new concepts, but also the liberation and enlightenment for modern curriculums. Some points of views in the modern curriculum theories can solve the contradictions between modern higher personnel training and demands of talents which are worthy of reflection and learning.

(1) Establish of curriculum system for innovative talents training

With the rapid socio-economic and technological development, the social demands for talents are changing. Generally speaking, the social demands for innovative talents will not change in a short time. Therefore, the university curriculum should mainly cultivate the innovation consciousness. The openness, richness, and diversity description in the post-modern curriculum point of view meet the requirements for new ideas and new methods in curriculum reform. The curriculum reform should focus on innovative talents cultivation. Therefore, the objectives of university curriculum should not only evaluate the knowledge learnt, but also cultivate the innovative ability, train the thinking ability and improve the overall ability. Additionally, the curriculum contents for colleges should break the traditional knowledge structures. Teachers should set the teaching contents by the features and situations of different students and the different curriculum objectives. In the classroom, teachers should let each student involving in the class, stimulate students' initiative, and build a harmonious classroom atmosphere. The curriculum implementation should abandon the traditional "indoctrination" or "lecturing" to adopt the flexible and diverse teaching ways. In addition, the teaching activities should abandon the traditional final evaluation. The curriculum performance should be evaluated by the combination of quality and quantity and that of procedure and results from different aspects.

(2) Improve the teaching levels of the teachers

The higher education reform is mainly implemented by teachers, so the teachers must have a wealth of expertise and a higher overall quality. The modern curriculum theory system is not in favor of the dominant position of the teacher which is the same as the advocate-"students are the main parts in teaching". However, in the actual teaching process, the status of teachers cannot be ignored. The university courses should have good teachers to guide and explain to generate good effects. The college reform requires that the teachers must make the appropriate changes accordingly. The teacher should have new educational concepts, students view and the view of the course to educate students. Only teachers accept the first shaping of curriculum reform, they can guide the students to better adapt the curriculum. Therefore, the teachers should have broad perspectives and deep expertise foundations to prepare for the curriculum reform. In addition, the teachers should be familiar with a variety of teaching methods to attract the students and cultivate their interests in order to promote the development of curriculum reform.

(3) Establish a service management system

The current university education has prevalent issues, such as single education formats, old-fashioned teaching contents and other issues. One of the reasons is the unreasonable curriculum management. The modern university management has lots of constrains, which are not good for cultivating student to think from many aspects and solve problems. Therefore, the curriculum should first change the previous management to build modern service-oriented management. The service-oriented curriculum management is a kind of curriculum modes with more flexibility, such as the selection of textbooks, the teaching methods and positions, and the teaching evaluation. All of these are not fixed and can be arranged with different situations. In addition, reducing the qualitative requirements for course contents, teaching method and examinations will make the curriculum not constrained and guided by the curriculum management. The curriculum management maximizes the guarantee and support for course implementation to increase the flexibility of teaching for providing a good environment for the creative development of students. 


\section{Conclusion}

In summary, the application of post-modern curriculum theories provides a broad development space for university education, which provides a new way of thinking and a relatively cutting-edge curriculum reform theory system. Although there are some defects, the paper proposes good development modes integrating the modern and post-modern curriculum theories which rebuild the modern university curriculum system to enhance the real effects of university education and solve the contradictions between talents cultivation and personnel training demands.

\section{References}

[1] Cheng Fang-fang. Constructive postmodernism and the reform of basic education course [J]. Tokyo Literature, 2012 (3): 190-191.

[2] Sun Dong-mei, Xu Lai-qun. The postmodern curriculum theory construction research university in our country course of enlightenment [J]. Journal of Contemporary Education Forum, 2005(9): 77-79.

[3] Cheng Min. Postmodernism imprint of the curriculum reform in colleges and universities [J]. Journal of Heilongjiang Institute of education, 2008, 27(11): 62-64.

[4] Li Xiong-ying. Postmodern curriculum theory perspectives of university curriculum reform in China [J]. Journal of Coal Higher Education, 2011, 29(4): 11-14.

[5] Jiang Ji-lan. Doll's post-modern perspective on curriculum enlightenment on curriculum reform in our country [J]. Journal of Contemporary Education Forum, 2005(16): 80-83.

[6] Li Ling-ying. The postmodern curriculum in higher vocational education curriculum reform revelation [J]. Journal of Education Theory and Practice, 2012, 21(32): 20-21.

[7] Zou Hai-yan. Based on postmodern horizon reconstruction of higher education curriculum [J]. China's Higher Education Research, 2009, 5(11): 80-82. 